\title{
Therapeutic options for bronchiolitis obliterans syndrome after lung transplantation
}

\author{
Nina Hangartner, Macé Matthew Schuurmans, Christian Murer, Christian Benden, \\ Lars Christian Huber
}

Division of Pulmonology, University Hospital Zurich, Zurich, Switzerland

\begin{abstract}
The development of chronic lung allograft dysfunction (CLAD) is one of the major obstacles following lung transplantation and limits patients' long-term outcome. Within the group of emerging CLAD phenotypes, bronchiolitis obliterans syndrome is the most common form and observed in up to $75 \%$ of lung transplant recipients 10 years after transplantation. Therapeutic options to address BOS are limited and, at our center, include modification of immunosuppression, immunomodulation using macrolide antibiotics, the use of statins, leukotriene receptor antagonists, and extracorporeal photopheresis. The evidence for most of these therapy options is derived from case reports or small, descriptive studies, whereas controlled trials are yet to be conducted. In the context of an illustrative case report, we review hereby the current literature regarding these different treatment options.
\end{abstract}

Keywords: Bronchiolitis obliterans syndrome, chronic allograft dysfunction, lung transplantation, treatment

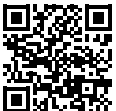

Received Date: 21.04 .2016 Accepted Date: 02.05 .2016

Available Online Date: 12.07.2016

DOI: $10.5152 /$ ejp.2016.92486

Corresponding Author

Lars Christian Huber

E-mail: lars.huber@usz.ch

- Available online at www.eurasianjpulmonol.com

This work is licensed under a Creative Commons Attribution-NonCommercial

\section{INTRODUCTION}

The development of chronic lung allograft dysfunction (CLAD) is one of the major obstacles following lung transplantation and limits patients'long-term outcome. Within the group of emerging CLAD phenotypes, bronchiolitis obliterans syndrome is the most common form and observed in up to $75 \%$ of lung transplant recipients 10 years after transplantation. We briefly present a typical case that illustrates many aspects encountered in the context of CLAD and CLAD management.

A 50-year-old patient with end-stage chronic obstructive pulmonary disease (COPD) complicated by frequent exacerbations underwent bilateral sequential lung transplantation. The patient was commenced on a standard immunosuppressive regimen with cyclosporine, mycophenolate mofetil, and corticosteroids. Anti-infective prophylaxis included trimethoprim/sulfamethoxazole, itraconazole, and, in the context of an intermediate risk constellation for cytomegalovirus (CMV donor negative/ recipient positive), valganciclovir. Since the patient developed post-transplant hypo-gammaglobulinemia (IgG $5.1 \mathrm{~g} / \mathrm{L}$; normal range 7.0-16.0 g/L), immunoglobulins were substituted intravenously on a regular basis. The early post-operative course was uneventful, and the patient was discharged from hospital at day 27 after transplantation.

Initially, the patient was seen on a weekly basis in the outpatient department and, due to an excellent allograft function and lack of infectious complications, this interval was further prolonged to a period of four to six weeks. Surveillance bronchoscopies were performed at month 2, 3, 4, and 6 after transplantation. Endobronchial inspection and differential cellularity of bronchoalveolar lavage were normal (i.e., at month 4 after lung transplantation: cell count $220 / \mu \mathrm{L}$, macrophages $94 \%$, neutrophil granulocytes 3.5\%, lymphocytes $3 \%$ ). Transbronchial biopsies did not show signs of infection or acute cellular rejection (ISHLT AOB0). Allograft function peaked 3 months after transplantation with a forced expiratory volume in $1 \mathrm{~s}\left(\mathrm{FEV}_{1}\right)$ of $4250 \mathrm{~mL}(120 \%$ of predicted). 
Eleven months after transplantation, the patient presented with symptoms of an upper respiratory tract infection and signs of inflammation (C-reactive protein $22 \mathrm{mg} / \mathrm{L}$, leukocyte count $11 \mathrm{G} / \mathrm{L}$ ). Lung function testing showed a significant decrease of $\mathrm{FEV}_{1}$ to $3120 \mathrm{~mL}$ (73\% of best $\mathrm{FEV}_{1}, \mathrm{FEV}_{1} / \mathrm{FVC} 81 \%$ ). However, pharyngeal swabs did not detect any pathogens (normal oral microflora, negative virology multiplex PCR). The patient was empirically treated with piperacillin/ tazobactam. Since symptoms and lung function recovered incompletely, chest computed tomography (CT) and bronchoscopy were performed. The CT findings were unremarkable, but transbronchial biopsies revealed cellular allograft rejection (ISHLT A2B0), probably triggered by the precedent respiratory tract infection. Pulse steroid therapy (1 g methyl-prednisolone intravenously for 3 days, followed by an oral taper) was administered and the calcineurin-inhibitor therapy was switched from cyclosporine to tacrolimus. Since transbronchial biopsy was complicated by the development of an iatrogenic pneumothorax requiring a chest drain insertion, lung function monitoring had to be paused until complete radiological resolution. Bronchoscopy follow-up 4 weeks later showed no evidence of an ongoing acute cellular rejection (ISHLT AOB0). However, lung function deteriorated further with an obstructive pattern in lung function testing.

Chest $\mathrm{CT}$, which had been unremarkable at the time of acute cellular rejection, now showed tree-in-bud lesions and progressive air trapping, compatible with the development of bronchiolitis obliterans syndrome (BOS, classification displayed in Table 1). Macrolide therapy with azithromycin was established with an immunomodulatory dose (250 mg three times weekly) and extracorporeal photopheresis (ECP) was started subsequently thereafter. However, ECP had to be stopped after 8 treatment cycles since the health insurance company denied further financial reimbursement. Thus, treatment with the leukotriene receptor antagonist montelukast (10 mg once daily) and the HMG-CoA-reductase inhibitor pravastatin was established. Lung function further decreased despite all interventions (nadir of FEV $610 \mathrm{~mL}, 14 \%$ of best $\mathrm{FEV}_{1}$, and FEV $/$ FVC 40\%). Due to an excellent clinical course during the first year post-transplantation and no evidence for failure of other organ systems other than severe chronic lung allograft dysfunction, the patient was evaluated for re-transplantation and listed 18 months after primary transplantation. Lung functional course and therapeutic interventions are summarized in Figure 1.

Long-term success of lung transplantation, as exemplified by this case report, is mainly limited by the development of chronic lung allograft dysfunction (CLAD). Different CLAD phenotypes have recently been described (1, 2). However, "classical" bronchiolitis obliter-

Table 1. BOS classification (based on spirometry)

\begin{tabular}{|l|l|}
\hline BOS Grade & $\% F_{1}$ of best post-transplant $\mathrm{FEV}_{1}$ \\
\hline 0 & $>90$ \\
$0-p$ & $81-90$ \\
1 & $66-80$ \\
2 & $50-65$ \\
3 & $<50$ \\
\hline
\end{tabular}

BOS: Bronchiolitis obliterans syndrome; $\mathrm{FEV}_{1}$ : forced expiratory volume in $1 \mathrm{~s}$

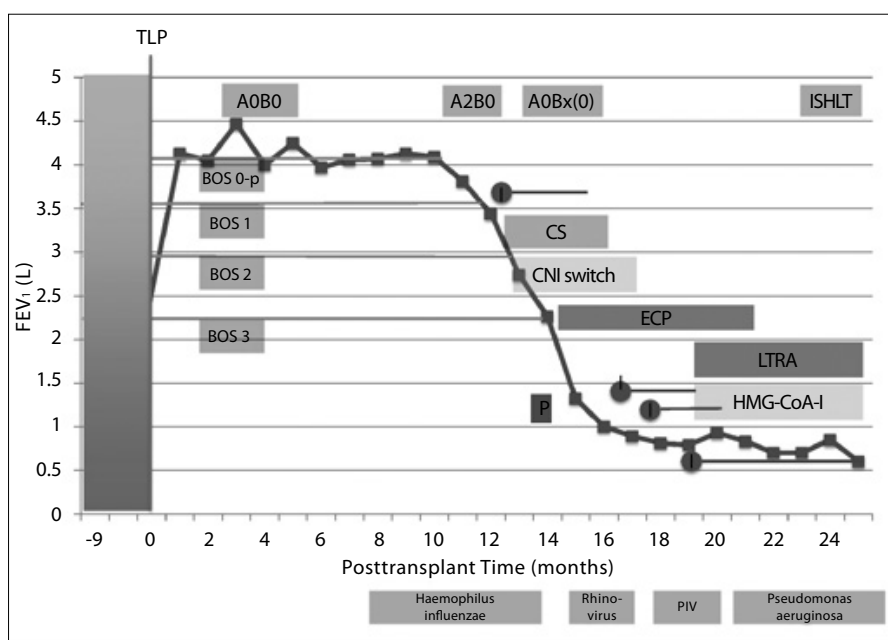

Figure 1. Illustrative course in a lung transplant recipient developing bronchiolitis obliterans syndrome (BOS)

Major complications, infections, lung functional decline, BOS severity, and treatment are shown. $\mathrm{P}$ (in red box) denotes development of Pneumothorax, I (in red circle) pulmonary infections. Infectious complications include Haemophilus influenzae, rhinovirus, parainfluenzavirus, and Pseudomonas aeruginosa (according to chronologous detection)

CS: Corticosteroids; CNI switch: calcineurin-inhibitor switch; ECP: extracorporeal photopheresis; LTRA: lung transplantation; HMG-CoA-l: 3-hydroxy-3-methylglutaryl coenzyme A (HMG-CoA) reductase inhibitor (statin therapy)

ans syndrome (BOS) remains the most common form of CLAD and is observed in about $50 \%$ of lung transplant patients after 5 years and in more than $75 \%$ of patients after 10 years following lung transplantation (3). This article aims to review current practice and published evidence (Table 2 ) for treatment of BOS.

\section{Therapeutic Options}

\section{Modification of Immunosuppression}

In the absence of contraindications, all lung transplant patients at our center receive a triple immunosuppressant therapy consisting of calcineurin inhibitors (CNIs), an antimetabolite, and corticosteroids. Inhibition of calcineurin interferes with the synthesis of interleukins, and as such, with the activation of T-lymphocytes. Cyclosporine and tacrolimus are the most commonly used CNIs. Whether tacrolimus is more efficient in preventing episodes of acute rejections and whether cyclosporine or tacrolimus is the preferred agent to delay the development of $\mathrm{BOS}$ is a controversial issue (4).

A prospective trial showed significant reduction in the development of BOS in the tacrolimus group as compared to the cyclosporine group (38\%) (5). However, this effect could not be confirmed at long-term follow-up. Similarly, Zuckermann et al. (6) could not show significant long-term differences between tacrolimus and cyclosporine therapy. Since a trend towards a decreased rejection rate was observed in patients on tacrolimus, the authors suggested the use of tacrolimus for patients at high risk for the development of allograft rejection. Along this line, Hachem et al. (7) reported a significant difference between patients treated with tacrolimus and cyclosporine. In tacrolimus-treated patients, the incidence of acute cellular rejection and lymphocytic bronchiolitis was significantly lower and a trend towards less development of BOS was observed. Treede et 
Table 2. Overview of available evidence by study design for CLAD/BOS

\begin{tabular}{|l|c|c|c|c|}
\hline & RCT & Observational & Experimental & Pilot study \\
\hline CNI Switch & 4 & 6 & 2 & 2 \\
Macrolide antibiotics & 2 & 2 & 1 & 1 \\
HMG-CoA-Inhibition & & 2 & 2 & 1 \\
Leukotriene receptor antagonist & & & & 1 \\
\hline Extracorporeal Photopheresis & & 8 & & 1 \\
\hline
\end{tabular}

BOS: Bronchiolitis obliterans syndrome; CLAD: chronic lung allograft dysfunction; CNI: calcineurin inhibitor; HMG-CoA-inhibition: 3-hydroxy-3-methylglutaryl coenzyme A inhibition; RCT: randomized controlled trial

al. (8) found a significantly lower incidence of BOS in patients treated with tacrolimus than with cyclosporine over a period of 3 years. The underlying mechanisms that explain the lower rate of BOS in patients treated with tacrolimus remain unclear but, at least in part, might be due to the observation that mesenchymal cells obtained from BOS patients that were converted from closporine to tacrolimus express reduced levels of collagen and other extracellular matrix proteins following the CNI switch (9).

Although these studies address the potential benefits and risks of tacrolimus versus cyclosporine used immediately after transplantation, the question whether patients should be switched from cyclosporine to tacrolimus following the development of BOS is even less resolved. In this context, several small retrospective studies analyzed the specific benefits of such conversion. Our literature search identified five small studies $(5,10-13)$ in which the majority of patients who switched to tacrolimus showed reduced $\mathrm{FEV}_{1}$ decline. In the largest retrospective study so far, Sarahrudi et al. (14) analyzed 244 patients from 13 institutions and reported fewer acute cellular rejection episodes and a reduction of $\mathrm{FEV}_{1}$ decline in BOS patients. The benefits of $\mathrm{CNI}$ conversion to tacrolimus could also be observed in

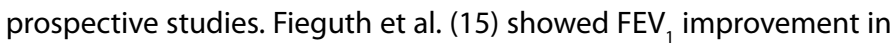
6 of 7 new-onset BOS patients, and data of Borro et al. (16) showed an overall reduction of $\mathrm{FEV}_{1}$ decline in $79 \mathrm{BOS}$ patients.

Based on these studies, CNI switch is commonly practiced at many institutions after the development of BOS, but randomized clinical trials are yet to be conducted. Future clinical studies have also to evaluate the best timing for a CNI switch.

\section{Macrolide Antibiotics}

Macrolide antibiotics, normally used as antimicrobial treatment, have additional immunomodulatory properties: It is known that even in low doses, azithromycin and clarithromycin increase the phagocytosis of apoptotic cells by alveolar macrophages and inhibit the production and release of pro-inflammatory cytokines (including IL-8 and tumor necrosis factor [TNF] alpha). Moreover, macrolides increase apoptosis of neutrophils and inhibit neutrophil adhesion to epithelial cells (17). The integrity of the epithelial barrier plays a major role in the defense of pathogens. Within the airways of the lung, this barrier is formed by a mucus layer, cellular junctions, cellular polarity, and a chemical defense. It was shown that macrolides modulate the expression of mucin genes and interact with protein production. Clarithromycin, for example, was found to inhibit hyper- and metaplasia of goblet cells. Whether macrolides have a direct impact on ion movement and altered cellular polarity due to abnormal mucus clearance or cellular junctions is unclear. In this context, azithromycin increased the production of cell occlusion proteins suggesting stabilization of the physical barrier. However, a consistent effect of macrolides on defensins could not be observed (18).

Experimental evidence for macrolide therapy in lung transplantation was obtained in a rat model using tracheal allografts. Remund et al. (19) analyzed the progression of BOS in these allografts and pre-emptive treatment with clarithromycin, probably by reduced expression of TNF-alpha and interferon (IFN)-gamma, completely prevented the tracheal lumen from obliteration.

The use of macrolide therapies in lung transplant recipients with CLAD/BOS was first suggested by two open-label pilot studies (20, 21). These studies, performed in a small number of lung transplant recipients, investigated whether the beneficial immunomodulatory effect of macrolide therapy observed in patients with cystic fibrosis and pan-bronchiolitis can also be observed in patients with established BOS. The results for this treatment modality were promising

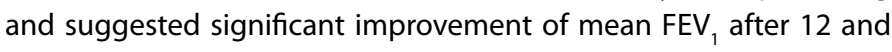
36 weeks of treatment, respectively.

Further studies confirmed the beneficial effect of macrolides in a cohort of lung transplant patients with BOS observing an increase of $\mathrm{FEV}_{1}$ in $30 \%$ of treated patients after six months (22). A recent controlled trial randomized BOS patients to receive azithromycin or placebo. Comparison of lung function 12 weeks after beginning

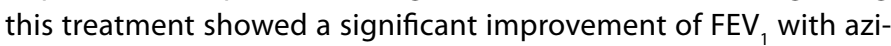
thromycin (mean $35 \mathrm{~mL}$ ) (23). Conversely, one follow-up trial did not detect improvements in lung function after the introduction of macrolide therapy and concluded that macrolides have no role in the treatment of the declining lung function due to chronic rejection (24).

Benden and Boehler (25) reported the experience with clarithromycin therapy in 31 lung transplant recipients followed for 12 months. Improvement of lung function was observed in 12 patients. This study suggested that the two macrolide regimens are of similiar efficacy. However, the magnitude of interactions and the fact that a substantially reduced number of pills required when using azithromycin as compared to clarithromycin might explain the preference of most centers for azithromycin in the context of immunomodulation for lung transplant recipients. 
Based on these data, it is common practice and suggested by current guidelines to establish macrolide therapy in immunomodulatory doses at onset of BOS as evidenced by lung functional decline and/or the development of air trapping in expiratory CT chest images (1). Since it is of interest not only to treat and stabilize CLAD/ BOS but rather to prevent its development, the question whether macrolide therapy should be established early post-transplant is of importance. In this context, the study by Vos et al. (26) is of major relevance. This randomized controlled trial conducted in a group of 83 lung transplant patients evaluated whether prophylactic azithromycin commenced at hospital discharge after transplantation might prevent the development of CLAD/BOS/chronic rejection measured as BOS-free survival 2 years after transplantation. These data showed a significantly lower occurrence of chronic rejection in patients on prophylactic azithromycin than in patients without it.

Moreover, macrolide therapy is used in lung transplant patients with the recently described phenotype of neutrophilic reversible allograft dysfunction (NRAD). This form of acute allograft dysfunction is characterized by neutrophilic alveolitis in the absence of infection. Patients with NRAD show an excellent response to azithromycin in therapeutic doses (27). However, a detailed discussion of this type of acute allograft dysfunction is beyond the scope of this review.

\section{HMG-CoA Inhibition}

Acting through inhibition of the 3-hydroxy-3-methylglutaryl coenzyme A (HMG-CoA) reductase, statins are widely used to reduce blood cholesterol levels. For this indication, statins are also employed in lung transplant recipients, in which, according to registry data, dyslipidemia is observed in $>20 \%$ of patients after 1 year and in $>50 \%$ after 5 years following transplantation (28). However, statins have also been associated with immunomodulation and anti-inflammatory mechanisms. These pleiotropic effects are of special interest in recipients of solid organs. In this context, Johnson et al. (29) compared the outcomes of 39 lung transplant patients treated with statins and 161 patients without such a treatment. This study showed an increased overall survival of patients under statin treatment when followed-up for 6 years but was limited by its retrospective design. In study patients, both the incidence of acute allograft rejection and the development of BOS were less frequently observed. The reduced predominance of neutrophilic cells in bronchoalveolar lavage fluid in statin-treated patients was interpreted as independent indicator of statin efficacy to prevent allograft dysfunction. Of interest, none of the patients that received early anti-dyslipidemic treatment-i.e., within the first post-transplant year-were diagnosed with BOS during the observation phase.

Another retrospective study performed a propensity-matched analysis of 75 patients on pravastatin therapy and a control group of 340 lung transplant patients without pravastatin. In line with the data from Johnson et al, statin treatment was found to delay the develop-

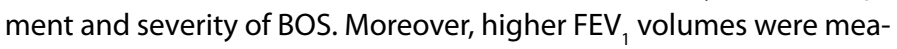
sured in statin-treated patients during the whole follow-up period and statin treatment prolonged the survival time significantly (30).

Two experimental studies using rat models might explain the immunomodulatory and immunosuppressive effects of statins: Ropponen et al. (31) studied the effects of Simvastatin on tracheal allograft recipients and observed early epithelial recovery due to enhanced cell proliferation under statin treatment and reduced development of obliterative airway disease. Another study compared the postoperative development of bronchiolitis obliterans in single lung transplanted animals with and without pravastatin therapy (32). Although allograft rejection occurred in all transplanted animals, pravastatin treated animals rejected the allograft significantly later than untreated rats. In both studies, statins were found to reduce significantly the amount of T-lymphocytes invading the allograft.

The above studies indicate beneficial effects of statin therapy for lung transplant patients independent of the presence of dyslipidemia. Since these effects appear to be most promising when established early after transplantation, controlled trials are needed to answer the question whether all lung transplant recipients should receive statins as part of their immediate post-transplant treatment regimen to prevent allograft rejection and the development of BOS.

\section{Leukotriene Receptor Antagonist}

Cysteinyl leukotrienes play an essential role in bronchoconstriction by increasing bronchial hyperreactivity and attracting eosinophils and neutrophils to the lamina propria (33). Additional effects of leukotrienes include increased vascular permeability and mucus hypersecretion. Leukotriene receptor antagonists (i.e., montelukast) suppress this pathway and, as such, are used as anti-inflammatory agents in asthma patients. Promising effects of montelukast therapy have also been observed on lung function in patients with pulmonary graft-versus-host (GvHD) disease (34). Since the lung pathology in GvHD and CLAD following lung transplantation share pathogenetic and morphologic features, Verleden et al. (35) conducted a pilot study with montelukast in azithromycin non-responsive CLAD/BOS patients. In eleven patients, treatment with montelukast resulted in a deceleration of the monthly $\mathrm{FEV}_{1}$ decline from $112 \mathrm{~mL}( \pm 26 \mathrm{~mL})$ before to $13 \mathrm{~mL}( \pm 13 \mathrm{~mL}) /$ month after initiation of treatment was observed, whereas no change in the control group occurred.

While these data are promising and support the use of montelukast in LTR developing BOS, controlled clinical trials should be conducted to corroborate the evidence of leukotriene receptor antagonist therapy. In this context, the results of a first randomized controlled trial using montelukast in lung transplant patients with CLAD have recently been presented and appear to confirm these findings (36).

\section{Extracorporeal Photopheresis}

Extracorporeal photopheresis (ECP) is leukopheresis-based phototherapy by which leukocytes are exposed to a photosensitizing agent and irradiation with UVA light outside of the patient. The underlying mechanisms of ECP have not fully been elucidated to date. However, major factors include the induction of apoptosis, modulation of $\mathrm{T}$ regulatory cells, and induction of immune tolerance (37-39).

Successful treatment of cutaneous T-cell lymphoma and acute cardiac allograft rejection by ECP encouraged Slovis et al. (40) in 1995 to treat six patients with CLAD resulting in stabilization of lung function in five cases. Further studies confirmed these data in a small number of patients $(41,42)$ while the study by Villanueva et al. (43) suggested a better effect of ECP in patients with early BOS. These data might be subjected to a lead time bias but still emphasize the importance of escalating therapy to prevent the progression of BOS/CLAD early. 
Benden et al. (44) reported the experiences with ECP for patients with BOS and recurrent acute cellular rejection episodes. Twelve patients diagnosed with BOS showed deceleration in the monthly decline of FEV from $112 \mathrm{~mL} / \mathrm{month}$ before the treatment to $12 \mathrm{~mL} / \mathrm{month}$ after ECP initiation. The largest retrospective study was conducted by Morrell et al. (45) with 60 patients followed for 7 years. Similarly, to the data reported by Benden et al. (44) this study observed a significant reduction in the monthly decrease of $\mathrm{FEV}_{1}(116 \mathrm{~mL} /$ month before treatment as compared to $28 \mathrm{~mL} /$ month after ECP). In $25 \%$ of ECP-treated patients, an increase in $\mathrm{FEV}_{1}$ was reported. The first prospective study was conducted by Jaksch et al. (46) comparing 143 patients under standardized treatment with 51 patients that were additionally treated with ECP. In $18 \%$ of ECP-treated patients, a sustained improvement of FEV for more than 1 year was observed, in 12\% lung functional improvement was found for 3 to 6 months and in $31 \%$ of patients' stabilization of lung function could be achieved. Of interest, differences between responders to ECP therapy as compared to non-responders included time of onset of BOS (early posttransplant development of BOS), kinetics of lung functional decline (slower decrease of lung function at the beginning of BOS) and BOS severity (lower BOS grade). A study by the Hannover group investigated the effects of ECP on different phenotypes of CLAD suggesting that patients with restrictive allograft syndrome (RAS), for example, respond less to ECP than patients with neutrophilic CLAD (47). Conversely, a recent study performed by Del Fante et al. (48) reported a 10 years follow-up of 48 CLAD patients treated with ECP, and in these patients, no association between $\mathrm{FEV}_{1}$ decline pattern and failure of ECP therapy or CLAD phenotype was found. However, the authors observed different survival rates of patients with different BOS phenotypes. This data is in line with our own experience (49). Moreover, a short time interval between transplantation and CLAD onset was correlated with a higher risk of ECP failure.

These findings imply that certain CLAD phenotypes (e.g., RAS) and faster initial progression of CLAD/BOS have a high failure risk for ECP treatment. Surprisingly, in this study, the failure rate of ECP patients could not be associated with poorer survival rates. Whether CLAD phenotypes have any role in predicting response to ECP therapy and survival of patients remains unclear. Current evidence supports our center's practice to offer ECP treatment to all CLAD patients independent of phenotypes as early as indicated; i.e. when other treatment options fail to show beneficial effects.

\section{CONCLUSION}

The development of CLAD/BOS remains one of the major obstacles following lung transplantation limiting its long-term success. In this review, we discussed the evidence for therapeutic options available to date to address BOS, including modification of immunosuppression, immunomodulation by macrolide antibiotics, use of statins and leukotriene receptor antagonists, and ECP. A summarizing algorithm to diagnose and treat BOS is provided in Figure $2(1,50)$. While some of these therapies used alone or in combination have shown beneficial effects, no intervention prevents or reverses CLAD/BOS and, as such, the development of novel therapies is urgently needed.

Peer-review: Externally peer-reviewed.

Author Contributions: Concept - L.C.H., N.H.; Supervision - L.C.H.; Literature Search - N.H., L.C.H.; Writing Manuscript - N.H., L.C.H.; Critical Review - M.M.S., C.M., C.B.

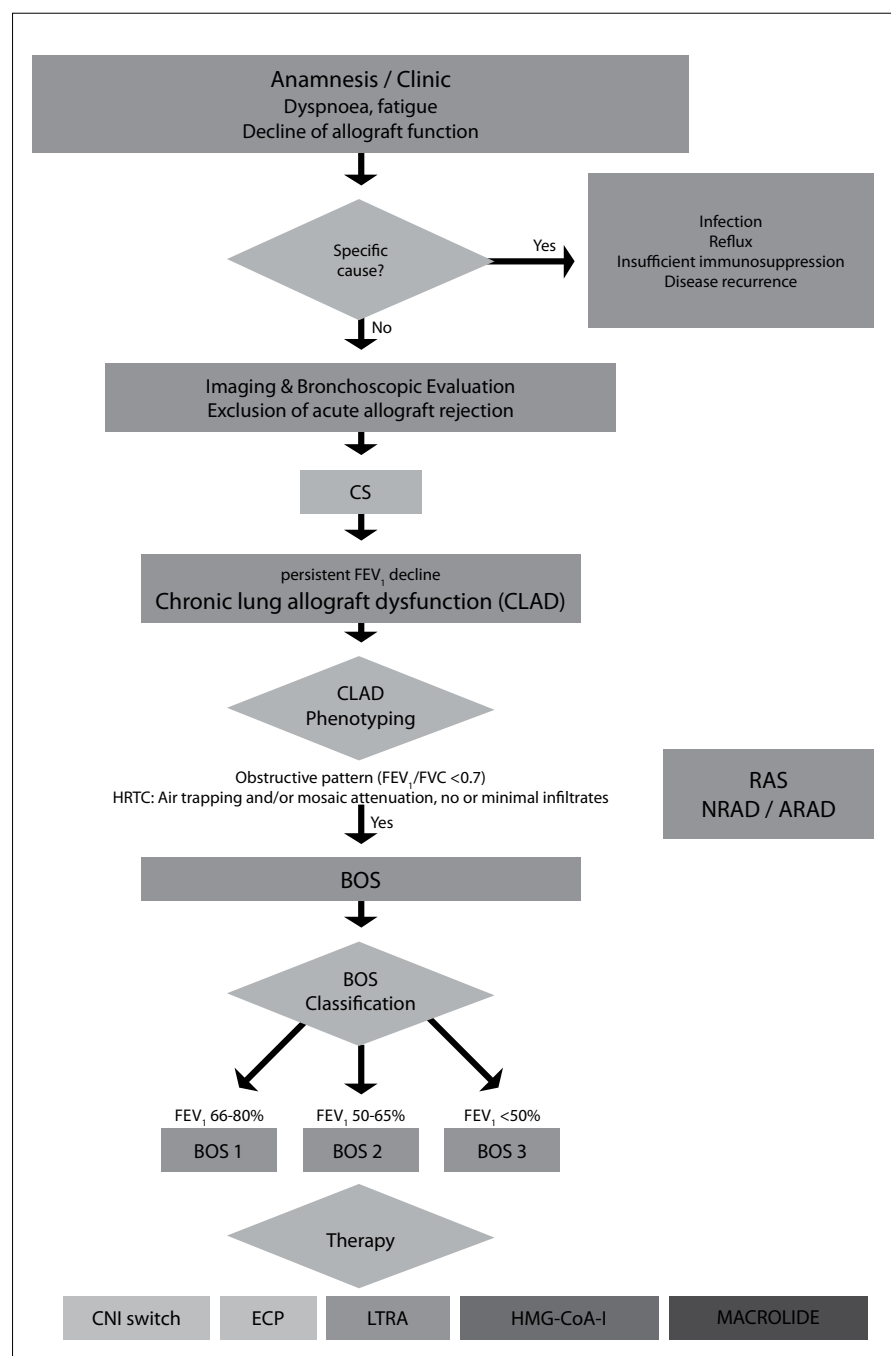

Figure 2. Algorithm to diagnose and treat $\mathrm{CLAD/BOS}$ as performed at the Zurich Lung Transplant Center [(adapted and modified from $(1,49)]$

ARAD: Azithromycin reversible allograft dysfunction; BOS: bronchiolitis obliterans syndrome; CNI switch: calcineurin-inhibitor switch; CS: corticosteroids; ECP: extracorporeal photopheresis; FEV; forced expiratory volume in $1 \mathrm{~s}$; HMG-CoA-l: 3-hydroxy-3-methylglutaryl coenzyme A (HMG-CoA) reductase inhibitor; LTRA: leukotriene receptor antagonist NRAD: neutrophilic reversible allograft dysfunction; RAS: restrictive allograft syndrome

Conflict of Interest: No conflict of interest was declared by the authors.

Financial Disclosure: The authors declared that this study has received no financial support.

\section{REFERENCES}

1. Verleden GM, Raghu G, Meyer KC, Glanville AR, Corris P. A new classification system for chronic lung allograft dysfunction. J Heart Lung Transplant 2014; 33: 127-33. [CrossRef]

2. Suwara MI, Vanaudenaerde BM, Verleden SE, Vos R, Green NJ, Ward C, et al. Mechanistic differences between phenotypes of chronic lung allograft dysfunction after lung transplantation. Transpl Int 2014; 27: 85767. [CrossRef]

3. Yusen RD, Christie JD, Edwards LB, Kucheryavaya AY, Benden C, Dipchand $\mathrm{Al}$, et al. The Registry of the International Society for Heart and Lung Transplantation: Thirtieth Adult Lung and Heart-Lung Transplant Report--2013; focus theme: age. J Heart Lung Transplant 2013; 32: 96578. [CrossRef] 
4. Penninga L, Penninga El, Møller $\mathrm{CH}$, Iversen $\mathrm{M}$, Steinbrüchel $\mathrm{DA}$, Gluud $\mathrm{C}$. Tacrolimus versus cyclosporin as primary immunosuppression for lung transplant recipients. Cochrane Database Syst Rev 2013; 5: CD008817. [CrossRef]

5. Keenan RJ, Konishi H, Kawai A, Paradis IL, Nunley DR, lacono AT, et al. Clinical trial of tacrolimus versus cyclosporine in lung transplantation. Ann Thorac Surg 1995; 60: 580-4. [CrossRef]

6. Zuckermann A, Reichenspurner H, Birsan T, Treede H, Deviatko E, Reichart $B$, et al. Cyclosporine $A$ versus tacrolimus in combination with mycophenolate mofetil and steroids as primary immunosuppression after lung transplantation: One-year results of a 2-center prospective randomized trial. J Thorac Cardiovasc Surg 2003; 125: 891-900. [CrossRef]

7. Hachem RR, Yusen RD, Chakinala MM, Meyers BF, Lynch JP, Aloush AA, et al. A Randomized Controlled Trial of Tacrolimus Versus Cyclosporine After Lung Transplantation. The Journal of Heart and Lung Transplantation 2007; 26: 1012-8. [CrossRef]

8. Treede H, Glanville AR, Klepetko W, Aboyoun C, Vettorazzi E, Lama R, et al. Tacrolimus and cyclosporine have differential effects on the risk of development of bronchiolitis obliterans syndrome: results of a prospective, randomized international trial in lung transplantation. J Heart Lung Transplant 2012; 31: 797-804. [CrossRef]

9. Stuckey LJ, Walker NM, Lin J, Chan KM, Lama VN. Halting BOS in Lung Transplant: Is Cyclosporine Conversion the Answer? J Heart Lung Transplant 2014; 33: S294. [CrossRef]

10. Ross DJ, Lewis MI, Kramer M, Vo A, Kass RM. FK 506 "rescue" immunosuppression for obliterative bronchiolitis after lung transplantation. Chest 1997; 112: 1175-9. [CrossRef]

11. Revell MP, Lewis ME, Llewellyn-Jones CG, Wilson IC, Bonser RS. Conservation of small-airway function by tacrolimus/cyclosporine conversion in the management of bronchiolitis obliterans following lung transplantation. J Heart Lung Transplant 2000; 19: 1219-23. [CrossRef]

12. Román A, Bravo C, Monforte V, Reyes L, Canela M, Morell F. Preliminary results of rescue therapy with tacrolimus and mycophenolate mofetil in lung transplanted patients with bronchiolitis obliterans. TPS 2002; 34: 146-7. [CrossRef]

13. Cairn J, Yek T, Banner NR, Khaghani A, Hodson ME, Yacoub M. Time-related changes in pulmonary function after conversion to tacrolimus in bronchiolitis obliterans syndrome. J Heart Lung Transplant 2003; 22: 507. [CrossRef]

14. Sarahrudi K, Estenne M, Corris P, Niedermayer J, Knoop C, Glanville A, et al. International experience with conversion from cyclosporine to tacrolimus for acute and chronic lung allograft rejection. J Thorac Cardiovasc Surg 2004; 127: 1126-32. [CrossRef]

15. Fieguth HG, Krueger S, Wiedenmann DE, Otterbach I, Wagner TO. Tacrolimus for treatment of bronchiolitis obliterans syndrome after unilateral and bilateral lung transplantation. Transplant Proc 2002; 34: 1884. [CrossRef]

16. Borro JM, Bravo C, Solé A, Usetti P, Zurbano F, Lama R, et al. Conversion from cyclosporine to tacrolimus stabilizes the course of lung function in lung transplant recipients with bronchiolitis obliterans syndrome. Transplant Proc 2007; 39: 2416-9. [CrossRef]

17. Robertson AG, Griffin SM, Murphy DM, Pearson JP, Forrest IA, Dark JH, et al. Targeting allograft injury and inflammation in the management of post-lung transplant bronchiolitis obliterans syndrome. Am J Transplant 2009; 9: 1272-8. [CrossRef]

18. Lopez-Boado YS, Rubin BK. Macrolides as immunomodulatory medications for the therapy of chronic lung diseases. Current Opin Pharmacol 2008; 8: 286-91. [CrossRef]

19. Remund K, Rechsteiner T, Guo Z, Rentsch K, Boehler A. The macrolide clarithromycin inhibits experimental post-transplant bronchiolitis obliterans. Exp Lung Res 2009; 35: 830-40. [CrossRef]

20. Gerhardt SG, McDyer JF, Girgis RE, Conte JV, Yang SC, Orens JB. Maintenance Azithromycin Therapy for Bronchiolitis Obliterans Syndrome. Am J Respir Crit Care Med 2003; 168: 121-5. [CrossRef]

21. Verleden GM, Dupont LJ. Azithromycin therapy for patients with bronchiolitis obliterans syndrome after lung transplantation. Transplantation 2004; 77: 1465-7. [CrossRef]
22. Gottlieb J, Szangolies J, Koehnlein T, Golpon H, Simon A, Welte T. Longterm azithromycin for bronchiolitis obliterans syndrome after lung transplantation. Transplantation 2008; 85: 36-41. [CrossRef]

23. Corris PA, Ryan VA, Small T, Lordan J, Fisher AJ, Meachery G, et al. A randomised controlled trial of azithromycin therapy in bronchiolitis obliterans syndrome (BOS) post lung transplantation. Thorax 2015; 70: 442-50. [CrossRef]

24. Shitrit D, Bendayan D, Gidon S, Saute M, Bakal I, Kramer MR. Long-term azithromycin use for treatment of bronchiolitis obliterans syndrome in lung transplant recipients. J Heart Lung Transplant 2005; 24: 1440-3. [CrossRef]

25. Benden C, Boehler A. Long-term clarithromycin therapy in the management of lung transplant recipients. Transplantation 2009; 87: 1538-40. [CrossRef]

26. Vos R, Vanaudenaerde BM, Verleden $\mathrm{SE}$, De Vleeschauwer SI, Willems-Widyastuti $A$, Van Raemdonck DE, et al. A randomised controlled trial of azithromycin to prevent chronic rejection after lung transplantation. Eur Respir J 2011; 37: 164-72. [CrossRef]

27. Verleden S, Vandermeulen E, Ruttens D, Vos R, Vaneylen A, Dupont L, et al. Neutrophilic reversible allograft dysfunction (NRAD) and restrictive allograft syndrome (RAS). Semin Respir Crit Care Med 2013; 34: 352-60. [CrossRef]

28. Christie JD, Edwards LB, Aurora P, Dobbels F, Kirk R, Rahmel AO, et al. Registry of the International Society for Heart and Lung Transplantation: twenty-fifth official adult lung and heart/lung transplantation report--2008. J Heart Lung Transplant 2008; 27: 957-69. [CrossRef]

29. Johnson BA, lacono AT, Zeevi A, McCurry KR, Duncan SR. Statin Use Is Associated with Improved Function and Survival of Lung Allografts. Am J Respir Crit Care Med 2003; 167: 1271-8. [CrossRef]

30. Li Y, Gottlieb J, Ma D, Kuehn C, Strueber M, Welte T, et al. Graft-protective effects of the HMG-CoA reductase inhibitor pravastatin after lung transplantation--a propensity score analysis with 23 years of follow-up. Transplantation 2011; 92: 486-92. [CrossRef]

31. Ropponen JO, Syrjälä SO, Hollmén M, Tuuminen R, Krebs R, Keränen MA, et al. Effect of simvastatin on development of obliterative airway disease: an experimental study. J Heart Lung Transplant 2012; 31: 194-203. [CrossRef]

32. Li Y, Köster T, Mörike C, V Hörsten S, Martin U, Bader M, et al. Pravastatin prolongs graft survival in an allogeneic rat model of orthotopic single lung transplantation. Eur J Cardiothorac Surg 2006; 30: 515-24. [CrossRef]

33. Laitinen LA, Laitinen A, Haahtela T, Vilkka V, Spur BW, Lee TH. Leukotriene E4 and granulocytic infiltration into asthmatic airways. Lancet 1993; 341: 989-90. [CrossRef]

34. Or R, Gesundheit B, Resnick I, Bitan M, Avraham A, Avgil M, et al. Sparing effect by montelukast treatment for chronic graft versus host disease: a pilot study. Transplantation 2007; 83: 577-81. [CrossRef]

35. Verleden GM, Verleden SE, Vos R, De Vleeschauwer SI, Dupont LJ, Van Raemdonck DE, et al. Montelukast for bronchiolitis obliterans syndrome after lung transplantation: a pilot study. Transpl Int 2011; 24: 651-6. [CrossRef]

36. Ruttens D, Verleden S, Vandermeulen E, Bellon H, Van Raemdonck D, Yserbyt J, et al. Montelukast for bronchiolitis obliterans syndrome after lung transplantation: a randomized controlled trial. J Heart Lung Transplant 2016; 35: S43-S4. [CrossRef]

37. Moss FM. New insights into the mechanism of action of extracorporeal phototherapy. Transfusion 2006; 46: 6-8. [CrossRef]

38. Knobler R, Berlin G, Calzavara-Pinton $P$, Greinix $H$, Jaksch $P$, Laroche L, et al. Guidelines on the use of extracorporeal photopheresis. J Eur Acad Dermatol Venereol 2014; 28 (Suppl 1): 1-37. [CrossRef]

39. Heshmati F. Updating ECP action mechanisms. Transfus Apher Sci 2014; 50: 330-9. [CrossRef]

40. Slovis BS, Loyd JE, King LE. Photopheresis for chronic rejection of lung allografts. N Engl J Med 1995; 332: 962. [CrossRef]

41. Salerno CT, Park SJ, Kreykes NS, Kulick DM, Savik K, Hertz MI, et al. Adjuvant treatment of refractory lung transplant rejection with extracorporeal photopheresis. J Thorac Cardiovasc Surg 1999; 117: 1063-9. [CrossRef] 
42. O'Hagan AR, Stillwell PC, Arroliga A, Koo A. Photopheresis in the treatment of refractory bronchiolitis obliterans complicating lung transplantation. Chest 1999; 115: 1459-62. [CrossRef]

43. Villanueva J, Bhorade SM, Robinson JA, Husain AN, Garrity ER. Extracorporeal photopheresis for the treatment of lung allograft rejection. Ann Transplant 2000; 5: 44-7.

44. Benden C, Speich R, Hofbauer GF, Irani S, Eich-Wanger C, Russi EW, et al. Extracorporeal photopheresis after lung transplantation: a 10-year single-center experience. Transplantation 2008; 86: 1625-7. [CrossRef]

45. Morrell MR, Despotis GJ, Lublin DM, Patterson GA, Trulock EP, Hachem RR. The efficacy of photopheresis for bronchiolitis obliterans syndrome after lung transplantation. J Heart Lung Transplant 2010; 29: 424-31. [CrossRef]

46. Jaksch P, Scheed A, Keplinger M, Ernst M-B, Dani T, Just U, et al. A prospective interventional study on the use of extracorporeal photopheresis in patients with bronchiolitis obliterans syndrome after lung transplantation. J Heart Lung Transplant 2012; 31: 950-7. [CrossRef]
47. Greer M, Dierich M, De Wall C, Suhling $H$, Rademacher J, Welte $T$, et al. Phenotyping established chronic lung allograft dysfunction predicts extracorporeal photopheresis response in lung transplant patients. Am J Transplant 2013; 13: 911-8. [CrossRef]

48. Del Fante C, Scudeller L, Oggionni T, Viarengo G, Cemmi F, Morosini M, et al. Long-Term Off-Line Extracorporeal Photochemotherapy in Patients with Chronic Lung Allograft Rejection Not Responsive to Conventional Treatment: A 10-Year Single-Centre Analysis. Respiration 2015; 90: 11828. [CrossRef]

49. Huber LC, Buergi U, Isenring B, Perret E, Schuurmans MM, Kohler M, et al. 5 years follow-up of lung transplant recipients undergoing extracorporal photophoresis. Eur Respir J 2014; 44 (Suppl 58): 3324.

50. Meyer KC, Raghu G, Verleden GM, Corris PA, Aurora P, Wilson KC, et al. An international ISHLT/ATS/ERS clinical practice guideline: diagnosis and management of bronchiolitis obliterans syndrome. Eur Respir J 2014; 44: 1479-503. [CrossRef] 